\title{
Local coexistence of native and invasive ant species is associated with micro-spatial shifts in foraging activity
}

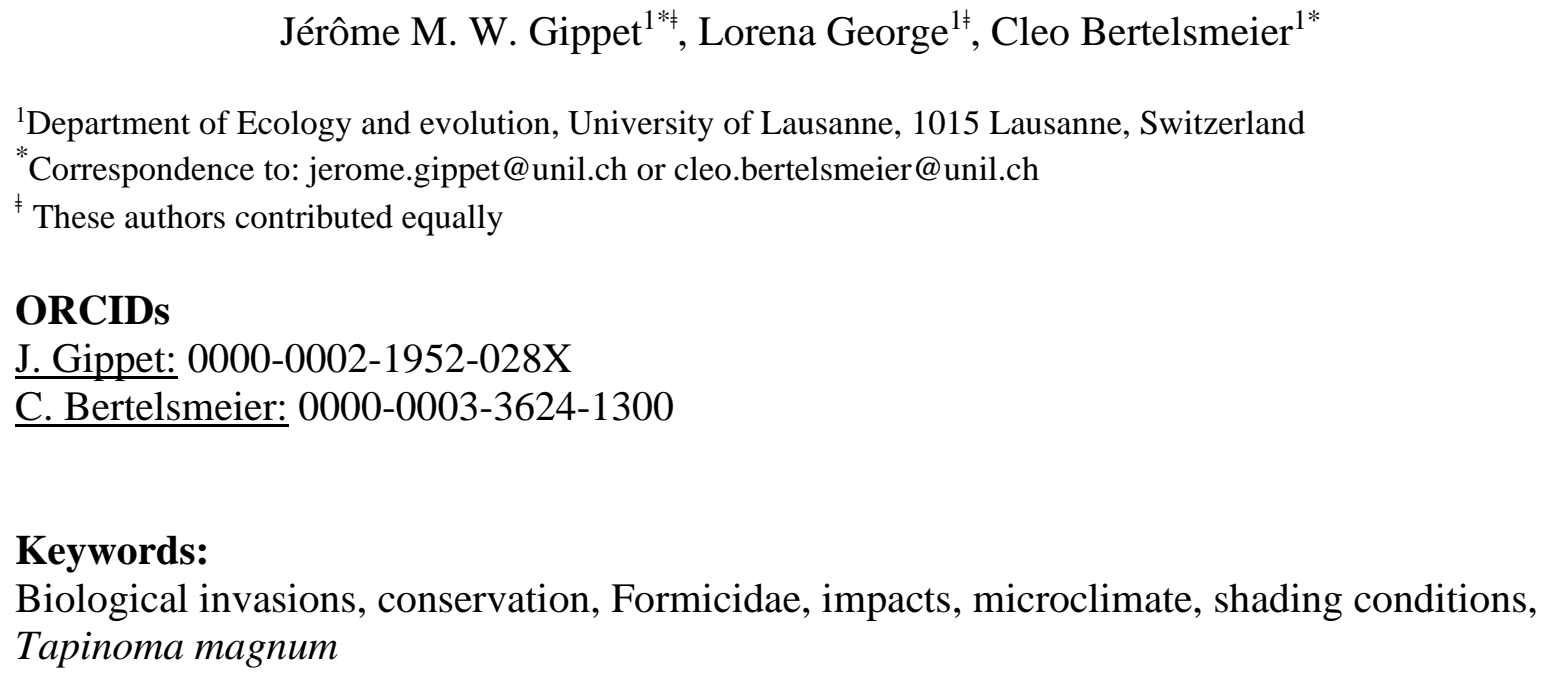

\section{Keywords:}

Biological invasions, conservation, Formicidae, impacts, microclimate, shading conditions, Tapinoma magnum

\section{This document includes:}

Main text

Table 1

Figures 1 to 5

Supplementary Table S1 and Figure S1

This file is the last version of the manuscript before acceptation for publication in Biological Invasions (www.springer.com/journal/10530).

The published paper can be found here: https://doi.org/10.1007/s10530-021-02678-2 


\section{Abstract}

33 Invasive species often displace native species by outcompeting them. Yet, some native species can persist even in heavily invaded areas. The mechanisms mediating this local coexistence are still unclear. Fine-scale microclimatic heterogeneity could promote the local coexistence of native and invasive animal competitors. We tested if native ant species could coexist with a recent ant invader, Tapinoma magnum, by shifting their foraging activity in time or space to different microclimatic conditions. We compared the foraging activity of native epigeic ant species among invaded and uninvaded sites. We collected ants at baits in green spaces on the north, east, south and west sides of buildings in the morning, at noon and in the afternoon to test if native species foraged under different microclimatic conditions in invaded sites. Invaded sites had lower ant species richness, diversity, and relative abundance. The native black garden ant Lasius niger - one of the most widespread Palearctic ant species - persisted at high densities

44 in invaded areas but foraged less on the east side of buildings and more on the west side. Microclimatic heterogeneity might promote native and invasive species coexistence by allowing some native species to shift their foraging behaviour to locally avoid or outcompete invasive competitors. Better understanding how fine-scale micro-environmental heterogeneity affects native species' persistence in invaded areas could help to predict and locally mitigate the negative impacts of biological invasions. 


\section{1 | INTRODUCTION}

52

Invasive species often displace their native competitors (Brown et al. 2002; Kenis et al. 2009; Wong et al. 2021) but some native species succeed in persisting even in heavily invaded areas (e.g., Achury, Holway, \& Suarez, 2020; Campbell, Frair, Gibbs, \& Rundell, 2015; da Silva Silveira \& Guimarães, 2020; Pacioglu et al., 2020). Yet, we know surprisingly little about how native animal species coexist locally with dominant invasive competitors, and in particular whether native species can modify their behaviour to avoid or decrease competition pressure with invaders (Berthon 2015; Ruland and Jeschke 2020).

Fine-scale environmental heterogeneity might promote the local coexistence of native and invasive competitors by allowing native species to shift their foraging or nesting habits towards environmental conditions where they can avoid or outcompete invasive competitors (Melbourne et al. 2007; Nielsen et al. 2010; Hart et al. 2017). Temperature and humidity are crucial components of species' nesting and foraging requirements and are thus expected to affect the local coexistence of competitor species (Albrecht and Gotelli 2001; Žagar et al. 2015; Paterson and Blouin-Demers 2017; Hoffacker et al. 2018). Small scale heterogeneity in thermal conditions are omnipresent in nature because they arise from the shades of geometrical features of the habitat such as terrain slopes, trees and human buildings (Napoli et al. 2016; Pincebourde et al. 2016).

However, the effect of microclimatic heterogeneity on the coexistence of native and invasive animals remains unclear. Existing research has focused mainly on temporal heterogeneity such as seasonal or daily variations in temperature (Holway 1998; Roeder et al. 2018), but it is still unknow if, at a local scale (i.e., within habitats), spatial heterogeneity in microclimatic conditions can promote the coexistence of native and invasive competitors. 
To address this question, we studied the effects of temporal and spatial microclimatic heterogeneity on the foraging activity of native and invasive ant competitors. Ants are an ideal model system to study the ecological effects of microclimatic conditions because they are small ectotherms whose nesting and foraging patterns are strongly influenced by variations in temperature (Spicer et al. 2017; Roeder et al. 2018). In addition, ants occupy every terrestrial landmass on Earth except Antarctica and thrive in human-altered environments such as urban and suburban areas (Pećarević et al. 2010). Urban ant communities do not strongly differ from adjacent non-urban communities but often comprise invasive species because human-mediated introduction events are more likely in urbanized areas (Perez and Diamond 2019; Dáttilo and MacGregor-Fors 2021). Moreover, urbanized areas are characterized by disturbed habitats that often favour invaders over native species (Holway et al. 2002b; Cadotte et al. 2017).

Invasive ants are among the fastest spreading and the most damaging animals worldwide (Rabitsch 2011). Most invasive ant species are behaviourally dominant competitors that form large colonies (sometimes called 'supercolonies') that can cover several hectares and are composed of hundreds to thousands of interconnected nests hosting thousands of queens and millions of workers (Holway et al. 2002a). Areas invaded by invasive ants are generally characterized by low native species richness and abundance compared to adjacent non-invaded areas (e.g., up to $90 \%$ decrease in abundance in areas invaded by the Red Imported Fire Ant (Solenopsis invicta); Porter \& Savignano, 1990; Wittman, 2014). Yet, native ant species frequently persist in areas heavily invaded by invasive ant species (Tartally 2006; Guénard and Dunn 2010; Vonshak et al. 2010; Wittman 2014). Understanding how microclimatic heterogeneity affects ant invasions is thus a conservation priority because it could help to limit the spread of invasive species and mitigate their impacts on native communities.

We used the shades generated by buildings as a source of temporal and spatial microclimatic heterogeneity. Variations in shading conditions are omnipresent in terrestrial environments. As 
surface temperature increases with the amount of absorbed solar radiation, shades can generate important microclimatic variations in space and time (Napoli et al. 2016; Pincebourde et al. 2016). To test if temporal and spatial microclimatic heterogeneity generated by buildings promote the coexistence of native and invasive ant species at local scale, we baited ants around residential buildings (on north, east, south and west sides) in the morning, at noon and in the afternoon (because shades' position changes along the day) in the presence or absence of a dominant invasive competitor: Tapinoma magnum.

Tapinoma magnum, probably native from northern Africa, is an emergent invasive species of great ecological and economic concern in Europe because it can easily establish and thrive in all Europe (Dekoninck et al. 2015; Janicki et al. 2016; Seifert et al. 2017), in contrast to most other invasive ants that are limited to the Mediterranean area. The species is probably transported with plant material (it was found in garden centres and tree nurseries; Dekoninck et al., 2015; Seifert et al., 2017) and several well-established populations are known in Belgium, France, Germany and Switzerland (Seifert et al. 2017; Bujan et al. 2021). The impacts of $T$. magnum on native biodiversity are still unknown but its dominant behaviour and supercolonial social structure (i.e., individuals mix freely within large supercolonies containing a high number of interconnected nests) suggest that the species is highly detrimental to native ant communities (Dekoninck et al. 2015; Warren et al. 2019).

In this study, we first tested the impact of T. magnum's invasion on the richness, diversity, relative abundance and composition of native epigeic ant communities and identified which species were able to coexist with T. magnum. Then, we tested if native ants that persisted in invaded areas changed their temporal foraging patterns or spatial location compared to noninvaded areas.

\section{2 | MATERIALS AND METHODS}




\subsection{Study sites}

Our study area is a residential area of the municipality of St-Sulpice, Switzerland (WGS84 coordinates: $46.51329,6.55624)$. This area is partially invaded by a large colony of Tapinoma magnum, covering at least four hectares. The species was detected in this area for the first time in 2012 but it is likely that it was introduced even earlier (D. Cherix, Pers. Comm.). In July 2019, we sampled ants at eight invaded and eight non-invaded sites. All sampling sites were in a homogenous environment composed of green spaces surrounding houses and buildings that are very similar in vegetation type and management intensity (i.e., short lawns with some bushes and trees). Each sampling site corresponded to a green space surrounding a residential building (buildings were constructed between 1974 and 2015; mean \pm SD: $1993 \pm$ 14) (Fig. 1a, b). We selected only large buildings (i.e. shortest side longer than 12 meters) surrounded by green spaces and with four sides accessible. For each site, sampling permission was obtained from the inhabitants of the building. Vegetation richness and height, dominant ground species, as well as the presence of bushes or trees were recorded for each sampling site. However, as these variables were consistent across sites, they were not included in the statistical analyses. Ground temperature has been linked to foraging intensity in ants (e.g., Azcárate et al. 2007). Thus, to verify that the time of the day and the side of building affected ground temperature we measured it using a thermometer probe (IHM multi-use digital stem thermometer 2263AT), during each sampling event and for each side of the building (at the most central point of the sampling area; see Fig. 1b).

\section{2 | Ant sampling}

Because shades follow the position of the sun during the day, each sampling site was sampled at three different times of the day: in the morning (between 7h00 and 10h30), at noon (between $12 \mathrm{~h} 00$ and 15h30) and in the afternoon (between $16 \mathrm{~h} 30$ and 20h00). For a given site, each of 
the three sampling events (morning, noon and afternoon) was conducted on a different day (Supplementary Data) to avoid that foraging trails created in the morning affect ants' foraging behaviour at noon and in the afternoon (Jackson et al. 2006). In addition, as it was not possible to sample several sites simultaneously (the sampling was performed by one person), this sampling design allowed to prevent a potential confounding effect between the day of sampling and the sampling site. Thus, a total of 48 sampling events were performed (16 sampling sites sampled three times; Fig. 1a). Each sampling event consisted of depositing 40 baits in the green space surrounding the building. The baits $(1,920$ baits in total) were Eppendorf tubes $(2 \mathrm{~mL})$ one-third filled with cotton impregnated with food. Since ant species can have different food preferences (Csata and Dussutour 2019), two types of Eppendorf tubes were prepared: 1,920 another 1,920 Eppendorf tubes were impregnated with tuna (50\% canned tuna and 50\% water solution). Thus, one bait corresponds to a pair of tubes. To record spatial variations in ants foraging activity, the 40 baits were evenly placed at each side of the building (10 to the north, 10 to the east, 10 to the south and 10 to the west; Fig. S1) in two transects of five baits (Fig. 1b). The first transect was one meter away from the building wall, whereas the second transect was four meters away from the first transect. On each transect, baits were placed every four meters. The exact position of baits could sometimes slightly differ from the ideal setup because of the presence of paved or partially inaccessible areas (building entry, parking lot). In these situations, baits were placed as close as possible from the ideal position, while keeping at least four meters between them (Fig. S1). Baits were placed around the buildings in a consistent way across all three sampling events. They were placed on the ground and left open for one hour, after which they were rapidly closed and collected in the same order in which they were deposited. Finally, baits were stored at $-20^{\circ} \mathrm{C}$ until species identification. All ants were counted and identified to either species or genus level using Seifert's (2007) ant identification key and 
then stored at $-20^{\circ} \mathrm{C}$ in $90 \%$ ethanol for long term conservation. Ants from the genus Temnothorax and Tetramorium were not identified to the species level because their morphological identification is not reliable (only two workers of Temnothorax were sampled, which is not enough to perform a proper identification in this genus, and Tetramorium species need to be identify with genetic markers or complex morphometrics; Wagner et al. 2017). Bait sampling is a common method to sample epigeic ants (i.e., ants foraging above ground) and is a classic tool to study competition between ant species as well as invasive ants' impacts on native ant communities (Porter and Savignano 1990; Bestelmeyer et al. 2000; Albrecht and Gotelli 2001; Thomas and Holway 2005; Roeder et al. 2018). However, this sampling method might not be suitable to detect and estimate the foraging activity of subterranean ant species (e.g., Lasius flavus) because they forage mostly underground. Finally, as ants can forage several meters away from their nest, this sampling design (i.e., baits every four meters) cannot differentiate between one colony foraging on several baits or multiple colonies foraging on one bait each.

\subsection{Microclimatic variations induced by shading conditions}

To control that ground temperature was linked to the time of the day (i.e., morning, noon and afternoon) and the side of the building (i.e., north, east, south and west), and that it did not differ among invaded and non-invaded sites, we used a Gaussian generalized mixed-effect model (R package 'glmmTMB'; Brooks et al. 2017) with ground temperature (in ${ }^{\circ} \mathrm{C}$ ) as the response variable and time of the day (morning, noon and afternoon), building side (north, east, south and west), zone (invaded and non-invaded) and their interactions as fixed effects, and sampling site and date as random effects ( $N=192$ measurements; Fig. 1c, d). We used analyses of deviance (i.e., Type III Wald $\chi^{2}$ tests) to assess which variables and interactions had significant effects on each response variables. Ground temperature was best explained by the 
interactive effect of time of the day and building side $\left(N=192, R_{\text {conditional }}^{2}=0.71, R_{\text {marginal }}^{2}=\right.$ 0.53; see Fig. 1d).

201

202

\section{4 | Effect of T. magnum on native ant communities}

We tested if the presence of T. magnum affected native ant species' richness, diversity and relative abundance, as well as their community composition. Native species richness was calculated as the number of native species, native species diversity as the Shannon diversity index (R package 'vegan'; Oksanen et al. 2020) and native species relative abundance as the proportion of baits occupied by native ant species by sampling events ( $N=48$ sampling events).

We compared the richness, diversity and relative abundance of native ant species between invaded and non-invaded sites using generalized linear mixed models (with Gaussian link functions for richness and diversity and Binomial link function for relative abundance) with sampling site and date as random effects observations (R package 'glmmTMB'). We visualized if the composition of native ant communities differed among invaded and non-invaded sites using Nonmetric Multidimensional Scaling (NMDS; R package 'vegan'). We also assessed differences in community composition among building side (north, east, south and west) and time of day (morning, noon, afternoon) NMDS simplifies multivariate data into a few important axes, allowing to better assess differences among groups. We computed the NMDS using the number of baits occupied by each species on each building side at each sampling event $(N=$ 192). We tested the differences in community composition between groups (invaded/noninvaded, north/east/south/west and morning/noon/afternoon) using permutational multivariate analyses of variance (PERMANOVA; R package 'vegan'). 
We measured the foraging activity of native and invasive ant species as the proportion of baits that they occupied at each building side (north, east, south, west) at each sampling event $(N=$ 192 building sides, 48 sampling events, 16 sampling sites; Fig. 1). We tested the interactive effects of T. magnum's presence, time of the day and building side on foraging activity in the four most frequent native ant species: Lasius niger, Myrmica specioides, Myrmica sabuleti and Tetramorium sp. These species occupied more than five percent of the baits in non-invaded sites (31\% for L. niger, $10 \%$ for M. specioides, $8 \%$ for M. sabuleti and $6 \%$ for Tetramorium sp.; Fig. 3). We also tested the effect of time of the day and building side on the foraging activity of T. magnum ( $N=96$ building side, 24 sampling events, 8 sampling sites; Fig. 1a). We used Binomial linear mixed models (R package ' $\mathrm{glmmTMB}$ ') to test the effects of invasion (invaded or non-invaded sites), time of the day (morning, noon or afternoon), building side (north, east, south or west) and all possible first-degree interactions on the proportion of baits occupied at each building side (10 baits were placed at each building side per sampling event). The sampling site and date were set as random effects to account for spatial and temporal dependency of observations(Brooks et al. 2017). For each model, we used a backward selection procedure to determine the best fitting model by sequentially removing non-significant fixed effects using type III Wald $\chi^{2}$ tests (R package 'car'; Fox \& Weisberg, 2019). We controlled for the validity of the best-fitting models by analysing models' residuals ( $\mathrm{R}$ package 'DHARMa'; Hartig 2018). Models' estimations and post hoc comparisons (with Tukey corrections) were computed using the R package 'emmeans' (Lenth 2020). Models' performance was assessed by computing pseudo- $\mathrm{R}^{2}$ using the $\mathrm{R}$ package 'performance' (Ludecke et al. 2019). All statistical analyses were performed in R 4.0.3 (R core team 2020).

\section{3 | RESULTS}

\section{1 | Effect of T. magnum on native ant communities}


We recorded 15 species from eight genera during this study (Fig. 3), which represents $\sim 20 \%$ of species occurring at regional scale (i.e., in the Vaud canton; www.fourmisvaud.ch) and $\sim 10 \%$ of species occurring in Switzerland (www.antmaps.org). T. magnum was the only non-native species detected. At non-invaded sites, Lasius niger was the most abundant species (mean \pm s.e. $=31 \pm 5 \%$ of baits occupied), followed by Myrmica specioides $(10 \pm 2 \%)$, Myrmica sabuleti (8 $\pm 3 \%)$ and Tetramorium sp. $(6 \pm 4 \%)$; other species occurred in $<5 \%$ of baits (Fig. 3$)$. In invaded sites, T. magnum was the most abundant species $(35 \pm 7 \%)$, followed by the Lasius niger $(30 \pm 2 \%)$, Myrmica specioides $(4 \pm 1 \%)$ and Tetramorium sp $(2 \pm 1 \%)$ (other species occurred in $\leq 1 \%$ of baits; Fig. 3). The presence of T. magnum was associated with lower richness $\left(\chi^{2}=11.1, d f=1, P<0.001\right.$; Fig. $\left.2 \mathrm{a}\right)$, relative abundance $\left(\chi^{2}=35, d f=1, P<0.0001\right.$; Fig. 2b) and diversity $\left(\chi^{2}=7.8, d f=1, P=0.005\right.$; Fig. 2 c) of native ant species. Yet, the total ant relative abundance differs only marginally between non-invaded and invaded sites $\left(\chi^{2}=\right.$ 3.5, $d f=1, P=0.06$; Fig. 3). The proportion of baits occupied by $M$. specioides and M. sabuleti was lower in invaded than in non-invaded sites (For M. specioides, $\chi^{2}=4.7, d f=1, P=0.03$; For M. sabuleti., $\chi^{2}=7.5, d f=1, P=0.006$; Fig. 3 ). However, the proportion of baits occupied by $L$. niger and Tetramorium sp. did not differ between invaded and non-invaded sites (For $L$. niger, $\chi^{2}=0.6, d f=1, P=0.45$; For Tetramorium sp., $\chi^{2}=1.3, d f=1, P=0.25$; Fig. 3 ). The composition of native ant communities was affected by $T$. magnum's invasion $\left(F=6.5, R^{2}=\right.$ $0.03, P=0.001)$ and by the time of the day $\left(F=6.9, R^{2}=0.07, P=0.001\right)$ but not by the side of the building $\left(F=1.03, R^{2}=0.02, P=0.4\right)$. However, the differences in community composition between invaded and non-invaded sites as well as between morning, noon and afternoon sampling were relatively small (Fig. 4).

\subsection{Effects of T. magnum on native ants' foraging activity in time and space}


The proportion of baits occupied by native species was affected by the time of the day in $M$. specioides $\left(\chi^{2}=29.5, d f=2, P<0.0001\right)$ and $M$. sabuleti $\left(\chi^{2}=12, d f=2, P=0.002\right)$ and by building side in $M$. sabuleti $\left(\chi^{2}=16.8, d f=3, P=0.0008\right)$, Tetramorium sp. $\left(\chi^{2}=14.6, d f=3\right.$, $P=0.002$; Table 1). Invasion and building side had an interactive effect on the probability of foraging on baits in L. niger $\left(\chi^{2}=13.5, d f=3, P=0.004\right.$; Table 1). Lasius niger was not affected by invasion on the north and south sides of buildings (odds ratio $=0.63$ and -0.36 respectively, $d f=180, P>0.05)$, but it was foraging less on the east side $($ odds ratio $=1.9, d f=180, P=$ 0.06), and more on the west side of buildings (odds ratio $=-2, d f=180, P=0.04$; Fig. 5) in invaded sites compared to non-invaded sites.

\section{4 | DISCUSSION}

Our field study demonstrated that Tapinoma magnum had a negative impact on native epigeic ant communities and should therefore be considered an important ecological threat for Europe and other temperate regions worldwide. We found that Lasius niger, the most abundant native ant in our study area, persisted in sites invaded by T. magnum and shifted its foraging activity spatially towards the west side of buildings compared to non-invaded sites where it was more active on the east side (Fig. 5). This suggests that west-exposed green spaces benefited L. niger by allowing the species to either avoid or outcompete $T$. magnum while the east-exposed green spaces would have the opposite effect. However, it is not clear why west-exposed green spaces favoured L. niger over T. magnum as they did not strongly differ in ground temperature from other building sides, contrarily to north-exposed areas that were up to $6^{\circ} \mathrm{C}$ cooler than other sides (Fig. 1d).

Our findings suggest that microclimatic heterogeneity promotes the persistence of L. niger in areas invaded by its invasive competitor T. magnum. Lasius niger is among the most 
widespread native species in the Palearctic realm (www.antmaps.org) and is notoriously abundant in open-vegetated habitats from urban cores to semi-natural areas (Gippet et al. 2017). Thus, L. niger is probably the most frequent native competitor for invasive ants in European landscapes and might be able to limit the spread of invasive ant species either by monopolizing available resources or physically dominating the invader. Our results are consistent with previous findings that invasive ants (Lasius neglectus) can be outcompeted by native competitors under certain environmental conditions (i.e., $>30^{\circ} \mathrm{C}$; Frizzi et al. 2017) and that $L$. niger is a challenging competitor that can limit the foraging success of highly invasive species such as Argentine ants (Linepithema humile ; Cordonnier, Blight, Angulo, \& Courchamp, 2020). However, it is possible that, over time, T. magnum can displace $L$. niger from baits (Thomas and Holway 2005; Carval et al. 2016). This is beyond the scope of our study which focused the ant's immediate foraging response by collecting ants one hour after placing the baits in the field. It is also unclear if the presence of T. magnum alters the spatial distribution of $L$. niger's colonies (i.e., fewer colonies of L.niger on the east-exposed green spaces), or if $L$. niger colonies maintained their pre-invasion spatial distribution but changed their foraging number of foragers recruited). Phenotypic plasticity in thermal tolerance, competitive could explore if it enables $L$. niger to persist in invaded areas.

In other native ant species (M. specioides and M. sabuleti), foraging activity uniformly decreased in invaded sites (Fig. 3, Table 1) and did not shift towards different time of day or building side (Table 1). This suggests that not all native species can modify the microclimatic conditions at which they forage in response to invasion, either because their plastic response is 
limited (e.g., great territoriality, limited foraging distance from nests) or because, in invaded sites, the two most dominant species $-T$. magnum and L. niger - already occupied most available resources (Savolainen and Vepsäläinen 1988). Behavioural shifts of native species (i.e., foraging or nesting) induced by the presence of an invasive competitor were observed in various native animals including fish, amphibians, reptiles, insects and molluscs (Thomson 2004; Alcaraz et al. 2008; Wright et al. 2010; Stuart et al. 2014; da Silva Silveira and Guimarães 2020) and it would therefore be interesting to assess to which extent the availability of alternative microenvironmental conditions help species to behaviourally respond to invaders or to find micro-refuges (Astorg et al. 2020).

Overall, native ant communities were poorer in invaded areas. However, our sampling method cannot evaluate $T$. magnum's impacts on subterranean ant communities because it detects only ground-foraging species. Yet, it is likely that T. magnum might have little or no impacts on subterranean ant species (eg, Lasius flavus) because they occupy a different ecological niche (Holway et al. 2002a). It also possible that we missed species that are present in the area because we collected baits after one hour. Future studies could thus combine several sampling methods (eg, baits and pitfall traps; Porter and Savignano 1990) or more intense baiting design ( eg, bait collection every hour over a 24 hours period; Albrecht and Gotelli 2001) to get a more complete picture of native ant communities in invaded and non-invaded sites. Our results show that $T$. magnum impacts native epigeic ant communities and suggest that the spread of this new invasive ant species might threaten other ground-dwelling arthropod taxa, as is the case with the invasion of Lasius neglectus, another highly invasive ant in Europe (Nagy et al. 2009).

To date, $\sim 40$ ant species have established invasive populations in Europe (Rabitsch 2011; Schifani 2019), yet, only Lasius neglectus and Tapinoma magnum (and to a lesser extent 
347 Linepithema humile), can grow large outdoor super-colonies in central and northern Europe,

348 while other invasive ant species are limited to the Mediterranean area (Ugelvig et al. 2008;

349 Charrier et al. 2020). Thus, the spread of T. magnum threatens all Europe and it is likely that

350 the species can established in other parts of the world if introduced by human activities such as

351 the global horticultural trade (Dekoninck et al. 2015; Seifert et al. 2017). Eradicating established invasive populations is costly, often fails and does not prevent reintroduction events (Pluess et al. 2012; Ujiyama and Tsuji 2018). Thus, it is urgent to manage this new invasion by preventing human-mediated dispersal of T. magnum to new locations (Gippet et al. 2019) and by limiting its impacts where it is already established (e.g., Guyot et al. 2015). Understanding how microclimatic conditions shape native and invasive species foraging activities offers promising insights to efficiently combat biological invasions. Taking advantage of microclimatic conditions might help design more target-specific eradication campaigns (Buczkowski et al. 2018) by, for example, depositing poisoned baits at the precise location and time that maximizes poison intakes by the invader and minimizes it for its native congeners. Finally, rather than trying to eradicate established invasive populations, it might sometimes be more efficient to mitigate their negative impacts by helping native species to locally outcompete them (Guo et al. 2018). In habitats that are particularly threatened by invasive species introductions (e.g., urban green spaces, residential areas), increasing microclimatic and more generally environmental heterogeneity may be an effective, environmentally friendly, cheap, and easy way to limit the impacts of invasive species. Homogenous habitats (e.g., lawns) could be avoided by creating microenvironmental heterogeneity in shading conditions (e.g., by planting trees or building artificial terrain slopes) but also in soil properties (e.g., type, compaction), vegetation management (i.e., heterogenous mowing; e.g., Suggitt et al. 2011) and in irrigation practices (i.e., heterogenous watering). 
371 Our results highlight the potential role of micro-environmental heterogeneity in mediating

372 native and invasive species coexistence. However, additional research is needed to generalize our findings and to address the mechanisms involved. Our study was performed in a single suburban area composed of very homogenous and highly maintained lawns. Replicating our experiment in other landscape contexts and seasons would thus allow to better assess the consistency of our findings across different urban areas as well as its validity in rural and seminatural habitats (e.g., pastures, meadows, scrublands). However, to replicate our experiment in other locations, adjacent invaded and non-invaded areas composed of similar non-homogenous habitats are required (e.g., Angulo et al. 2011). If this set-up is not possible, researchers may test the effects of micro-environmental heterogeneity on native and invasive ants' coexistence by experimentally adding shaded microhabitats to adjacent invaded/non-invaded environments (e.g., Wittman et al. 2010). This would allow generating microclimatic heterogeneity independently of the time of the day and to avoid the constraints linked to the utilization of buildings to generate shade as building walls are not always perfectly aligned with the cardinal directions. Yet, despite these limitations understanding the micro-environmental consequences of human buildings is interesting because invasive species often thrive in urbanized areas.

\section{5 | CONCLUSION}

Shades are an omnipresent source of spatial and temporal microclimatic heterogeneity. Yet, their consequences on species' foraging activity, community structure and their potential role in the local coexistence of native and invasive species are understudied (Stahlschmidt and Johnson 2018; Ibarra-isassi et al. 2021). This study is a first step towards understanding how shading conditions could mediate the local coexistence of native and invasive competitors and should stimulate future research to explore the effects of fine-scale environmental 
395 heterogeneity on native and invasive species coexistence and how these effects might change 396 across seasons or at other latitudes. 


\section{References}

Achury R, Holway DA, Suarez A V. (2020) Pervasive and persistent effects of ant invasion and fragmentation on native ant assemblages. Ecology 102:e03257. https://doi.org/10.1002/ecy.3257

Albrecht M, Gotelli NJ (2001) Spatial and temporal niche partitioning in grassland ants. Oecologia 126:134-141. https://doi.org/10.1007/s004420000494

Alcaraz C, Bisazza A, García-Berthou E (2008) Salinity mediates the competitive interactions between invasive mosquitofish and an endangered fish. Oecologia 155:205-213. https://doi.org/10.1007/s00442-007-0899-4

Angulo E, Caut S, Cerdá X (2011) Scavenging in Mediterranean ecosystems : effect of the invasive Argentine ant. Biol Invasions 13:1183-1194. https://doi.org/10.1007/s10530011-9953-6

Astorg L, Sanderson S, Côté-Gravel V, et al (2020) Different refuge types dampen exotic invasion and enhance diversity at the whole ecosystem scale in a heterogeneous river system. Biol Invasions 7:. https://doi.org/10.1007/s10530-020-02374-7

Azcárate FM, Kovacs E, Peco B (2007) Microclimatic conditions regulate surface activity in harvester ants Messor barbarus. J Insect Behav 20:315-329. https://doi.org/10.1007/s10905-007-9074-3

Balzani P, Vizzini S, Frizzi F, et al (2021) Plasticity in the trophic niche of an invasive ant explains establishment success and long-term coexistence. Oikos 130:691-696. https://doi.org/10.1111/oik.08217

Berthon K (2015) How do native species respond to invaders? Mechanistic and trait-based perspectives. Biol Invasions 17:2199-2211. https://doi.org/10.1007/s10530-015-0874-7

Bestelmeyer BT, Agosti D, Alonso LE, et al (2000) Field techniques for the study of grounddwelling ants: An overview, description, and evaluation. Ants Stand methods Meas Monit Biodivers 122-128

Brooks ME, Kristensen K, van Benthem KJ, et al (2017) glmmTMB balances speed and flexibility among packages for zero-inflated generalized linear mixed modeling. R J 9:378-400. https://doi.org/10.32614/rj-2017-066

Brown BJ, Mitchell RJ, Graham SA (2002) Competition for pollination between an invasive species (purple loosestrife) and a native congener. Ecology 83:2328-2336. https://doi.org/10.1890/0012-9658(2002)083[2328:CFPBAI]2.0.CO;2

Buczkowski G, Mothapo NP, Wossler TC (2018) Let them eat termites-prey-baiting provides effective control of Argentine ants, Linepithema humile, in a biodiversity hotspot. J Appl Entomol 142:504-512. https://doi.org/10.1111/jen.12501

Bujan J, Charavel E, Bates OK, et al (2021) Increased acclimation ability accompanies a thermal niche shift of a recent invasion. J Anim Ecol 90:483-491. https://doi.org/10.1111/1365-2656.13381

Bujan J, Roeder KA, Yanoviak SP, Kaspari M (2020) Seasonal plasticity of thermal tolerance in ants. Ecology 101:1-6. https://doi.org/10.1002/ecy.3051

Cadotte MW, Yasui SLE, Livingstone S, MacIvor JS (2017) Are urban systems beneficial, 
detrimental, or indifferent for biological invasion? Biol Invasions 19:3489-3503. https://doi.org/10.1007/s10530-017-1586-y

Campbell SP, Frair JL, Gibbs JP, Rundell RJ (2015) Coexistence of the endangered, endemic Chittenango ovate amber snail (Novisuccinea chittenangoensis) and a non-native competitor. Biol Invasions 17:711-723. https://doi.org/10.1007/s10530-014-0763-5

Carval D, Cotté V, Resmond R, et al (2016) Dominance in a ground-dwelling ant community of banana agroecosystem. Ecol Evol 6:8617-8631. https://doi.org/10.1002/ece3.2570

Charrier NP, Hervet C, Bonsergent C, et al (2020) Invasive in the North: new latitudinal record for Argentine ants in Europe. Insectes Soc 67:331-335. https://doi.org/10.1007/s00040-020-00762-9

Cordonnier M, Blight O, Angulo E, Courchamp F (2020) The native ant Lasius niger can limit the access to resources of the invasive argentine ant. Animals 10:1-17. https://doi.org/10.3390/ani10122451

Csata E, Dussutour A (2019) Nutrient regulation in ants (Hymenoptera: Formicidae): a review. Myrmecological News 29:111-124. https://doi.org/10.25849/myrmecol.news

da Silva Silveira S, Guimarães M (2020) The enemy within: consequences of the invasive bullfrog on native anuran populations. Biol Invasions 23:373-378. https://doi.org/10.1007/s10530-020-02385-4

Dáttilo W, MacGregor-Fors I (2021) Ant social foraging strategies along a Neotropical gradient of urbanization. Sci Rep 11:1-9. https://doi.org/10.1038/s41598-021-85538-2

Dekoninck W, Parmentier T, Seifert B (2015) First records of a supercolonial species of the Tapinoma nigerrimum complex in Belgium (Hymenoptera: Formicidae). Bull Soc R Belg Entomol 151:206-209

Fox J, Weisberg S (2019) An R Companion to Applied Regression, Third Edition.

Frizzi F, Bartalesi V, Santini G (2017) Combined effects of temperature and interspecific competition on the mortality of the invasive garden ant, Lasius neglectus: A laboratory study. J Therm Biol 65:76-81. https://doi.org/10.1016/j.jtherbio.2017.02.007

Gippet JMW, Liebhold AM, Fenn-Moltu G, Bertelsmeier C (2019) Human-mediated dispersal in insects. Curr Opin Insect Sci 35:96-102. https://doi.org/https://doi.org/10.1016/j.cois.2019.07.005

Gippet JMW, Mondy N, Diallo-Dudek J, et al (2017) I'm not like everybody else: urbanization factors shaping spatial distribution of native and invasive ants are speciesspecific. Urban Ecosyst 20:157-169. https://doi.org/10.1007/s11252-016-0576-7

Guénard B, Dunn RR (2010) A new (Old), invasive ant in the hardwood forests of eastern North America and its potentially widespread impacts. PLoS One 5:1-10. https://doi.org/10.1371/journal.pone.0011614

Guo Q, Brockway DG, Larson DL, et al (2018) Improving ecological restoration to curb biotic invasion - A practical guide. Invasive Plant Sci Manag 11:163-174. https://doi.org/10.1017/inp.2018.29

Guyot V, Castagneyro B, Vialatte A, et al (2015) Tree diversity limits the impact of an invasive forest pest. PLoS One 10:1-16. https://doi.org/10.1371/journal.pone.0136469 
Hart SP, Usinowicz J, Levine JM (2017) The spatial scales of species coexistence. Nat Ecol Evol 1:1066-1073. https://doi.org/10.1038/s41559-017-0230-7

Hartig F (2018) DHARMa: Residual Diagnostics for Hierarchical (Multi-Level / Mixed) Regression Models. R package version 0.2.0.

Hoffacker M Lou, Cecala KK, Ennen JR, et al (2018) Interspecific interactions are conditional on temperature in an Appalachian stream salamander community. Oecologia 188:623-631. https://doi.org/10.1007/s00442-018-4228-X

Holway DA (1998) Effect of Argentine ant invasions on ground-dwelling arthropods in northern California riparian woodlands. Oecologia 116:252-258

Holway DA, Lach L, Suarez A V, et al (2002a) The causes and consequences of ant invasions. Annu Rev Ecol Syst 33:181-233

Holway DA, Suarez A V., Case TJ (2002b) Role of abiotic factors in governing susceptibility to invasion: A test with argentine ants. Ecology 83:1610-1619. https://doi.org/10.1890/0012-9658(2002)083[1610:ROAFIG]2.0.CO;2

Ibarra-isassi J, Handa IT, Arenas-Clavijo A, et al (2021) Shade-growing practices lessen the impact of coffee plantations on multiple dimensions of ant diversity. J Appl Ecol 1-12. https://doi.org/10.1111/1365-2664.13842

Jackson DE, Martin SJ, Holcombe M, Ratnieks FLW (2006) Longevity and detection of persistent foraging trails in Pharaoh's ants, Monomorium pharaonis (L.). Anim Behav 71:351-359. https://doi.org/10.1016/j.anbehav.2005.04.018

Janicki J, Narula N, Ziegler M, et al (2016) Visualizing and interacting with large-volume biodiversity data using client-server web-mapping applications: The design and implementation of antmaps.org. Ecol Inform 32:185-193. https://doi.org/10.1016/j.ecoinf.2016.02.006

Kenis M, Auger-Rozenberg MA, Roques A, et al (2009) Ecological effects of invasive alien insects. Biol Invasions 11:21-45. https://doi.org/10.1007/s10530-008-9318-y

Lenth RV (2020) emmeans: Estimated marginal means, aka least-squares means

Ludecke D, Makowski D, Waggoner P (2019) performance: assessment of regression models performance. $\mathrm{R}$ package version 0.4 .2

Melbourne BA, Cornell H V., Davies KF, et al (2007) Invasion in a heterogeneous world: Resistance, coexistence or hostile takeover? Ecol Lett 10:77-94. https://doi.org/10.1111/j.1461-0248.2006.00987.x

Nagy C, Tartally A, Vilisics F, et al (2009) Effects of the invasive garden ant, Lasius neglectus Van Loon, Boomsma \& András-Falvy, 1990 (Hymenoptera: Formicidae), on arthropod assemblages: pattern analyses in the type supercolony. Myrmecological News $12: 171-181$

Napoli M, Massetti L, Brandani G, et al (2016) Modeling tree shade effect on urban ground surface temperature. J Environ Qual 45:146-156. https://doi.org/10.2134/jeq2015.02.0097

Nielsen UN, Osler GHR, Campbell CD, et al (2010) The enigma of soil animal species diversity revisited: The role of small-scale heterogeneity. PLoS One 5:26-28. 
Oksanen J, Blanchet FG, Friendly M, et al (2020) vegan: Community Ecology Package

Pacioglu O, Theissinger K, Alexa A, et al (2020) Multifaceted implications of the competition between native and invasive crayfish: a glimmer of hope for the native's long-term survival. Biol Invasions 22:827-842. https://doi.org/10.1007/s10530-01902136-0

Paterson JE, Blouin-Demers G (2017) Do ectotherms partition thermal resources? We still do not know. Oecologia 183:337-345. https://doi.org/10.1007/s00442-016-3762-7

Pećarević M, Danoff-Burg J, Dunn RR (2010) Biodiversity on broadway - enigmatic diversity of the societies of ants (formicidae) on the streets of New York City. PLoS One 5:1-8. https://doi.org/10.1371/journal.pone.0013222

Perez A, Diamond SE (2019) Idiosyncrasies in cities: Evaluating patterns and drivers of ant biodiversity along urbanization gradients. J Urban Ecol 5:1-10. https://doi.org/10.1093/jue/juz017

Pincebourde S, Murdock CC, Vickers M, Sears MW (2016) Fine-scale microclimatic variation can shape the responses of organisms to global change in both natural and urban environments. Integr Comp Biol 56:45-61. https://doi.org/10.1093/icb/icw016

Pluess T, Cannon R, Jarošík V, et al (2012) When are eradication campaigns successful? A test of common assumptions. Biol Invasions 14:1365-1378. https://doi.org/10.1007/s10530-011-0160-2

Porter SD, Savignano DA (1990) Invasion of polygyne fire ants decimates native ants and disrupts arthropod community. Ecology 71:2095-2106

R core team (2020) R v.4.0.3: A Language and Environment for Statistical Computing. R Foundation for Statistical Computing, Vienna, Austria.

Rabitsch W (2011) The hitchhiker's guide to alien ant invasions. BioControl 56:551-572. https://doi.org/10.1007/s10526-011-9370-x

Roeder KA, Roeder D V., Kaspari M (2018) The role of temperature in competition and persistence of an invaded ant assemblage. Ecol Entomol 43:774-781. https://doi.org/10.1111/een.12663

Ruland F, Jeschke JM (2020) How biological invasions affect animal behaviour: A global, cross-taxonomic analysis. J Anim Ecol 89:2531-2541. https://doi.org/10.1111/13652656.13306

Savolainen R, Vepsäläinen K (1988) A competition hierarchy among boreal ants : Impact on resource partitioning and community structure. Oikos 51:135-155

Schifani E (2019) Exotic ants (Hymenoptera, Formicidae) invading Mediterranean Europe: A brief summary over about 200 years of documented introductions. Sociobiology 66:198208. https://doi.org/10.13102/sociobiology.v66i2.4331

Seifert B (2007) Die Ameisen Mittel- und Nordeuropas. Lutra Verlags- und Vertriebsgesellschaft, Tauer 368p

Seifert B, D'eustacchio D, Kaufmann B, et al (2017) Four species within the supercolonial ants of the Tapinoma nigerrimum complex revealed by integrative taxonomy 
Spicer ME, Stark AY, Adams BJ, et al (2017) Thermal constraints on foraging of tropical canopy ants. Oecologia 183:1007-1017. https://doi.org/10.1007/s00442-017-3825-4

Stahlschmidt ZR, Johnson D (2018) Moving targets: determinants of nutritional preferences and habitat use in an urban ant community. Urban Ecosyst 21:1151-1158. https://doi.org/10.1007/s11252-018-0796-0

Stuart YE, Campbell TS, Hohenlhole PA, et al (2014) Rapid evolution of a native species following invasion by a congener. Science 346:463-466

Suggitt AJ, Gillingham PK, Hill JK, et al (2011) Habitat microclimates drive fine-scale variation in extreme temperatures. Oikos 120:1-8. https://doi.org/10.1111/j.16000706.2010.18270.x

Tartally A (2006) Long term expansion of a supercolony of the invasive garden ant, Lasius neglectus (Hymenoptera: Formicidae ). Myrmecologische Nachrichten 9:21-25

Thomas ML, Holway DA (2005) Condition-specific competition between invasive Argentine ants and Australian Iridomyrmex. J Anim Ecol 74:532-542. https://doi.org/10.1111/j.1365-2656.2005.00952.x

Thomson D (2004) Competitive interactions between the invasive European honey bee and native bumble bees. Ecology 85:458-470. https://doi.org/10.1890/02-0626

Trigos-Peral G, Abril S, Angulo E (2021) Behavioral responses to numerical differences when two invasive ants meet: the case of Lasius neglectus and Linepithema humile. Biol Invasions 23:935-953. https://doi.org/10.1007/s10530-020-02412-4

Ugelvig L V, Drijfhout FP, Kronauer DJ, et al (2008) The introduction history of invasive garden ants in Europe: integrating genetic, chemical and behavioural approaches. BMC Biol 6:11

Ujiyama S, Tsuji K (2018) Controlling invasive ant species: A theoretical strategy for efficient monitoring in the early stage of invasion. Sci Rep 8:2-10. https://doi.org/10.1038/s41598-018-26406-4

Vonshak M, Dayan T, Ionescu-Hirsh A, et al (2010) The little fire ant Wasmannia auropunctata: A new invasive species in the Middle East and its impact on the local arthropod fauna. Biol Invasions 12:1825-1837. https://doi.org/10.1007/s10530-0099593-2

Wagner HC, Arthofer W, Seifert B, et al (2017) Light at the end of the tunnel: Integrative taxonomy delimits cryptic species in the $<\mathrm{i}>$ Tetramorium caespitum $<|\mathrm{i}\rangle$ complex (Hymenoptera: Formicidae). Myrmecological News 25:95-129

Warren RJ, Reed K, Mathew A, et al (2019) Release from intraspecific competition promotes dominance of a non-native invader. Biol Invasions 21:895-909. https://doi.org/10.1007/s10530-018-1868-Z

Wittman SE (2014) Impacts of invasive ants on native ant communities (Hymenoptera: Formicidae). Myrmecological News 19:111-123

Wittman SE, Sanders NJ, Ellison AM, et al (2010) Species interactions and thermal constraints on ant community structure. Oikos 119:551-559. 
https://doi.org/10.1111/j.1600-0706.2009.17792.x

603

604

605

606

607

608

609

610

611

612

613
Wong MKL, Tsang TPN, Lewis OT, Guénard B (2021) Trait-similarity and trait-hierarchy jointly determine fine-scale spatial associations of resident and invasive ant species. Ecography (Cop) 44:1-13. https://doi.org/10.1111/ecog.05505

Wright JT, Byers JE, Koukoumaftsis LP, et al (2010) Native species behaviour mitigates the impact of habitat-forming invasive seaweed. Oecologia 163:527-534. https://doi.org/10.1007/s00442-010-1608-2

Žagar A, Carretero MA, Osojnik N, et al (2015) A place in the sun: interspecific interference affects thermoregulation in coexisting lizards. Behav Ecol Sociobiol 69:1127-1137. https://doi.org/10.1007/s00265-015-1927-8 


\section{Acknowledgements}

615 This work was funded by the Swiss Canton Vaud, the Fond National Suisse, and the Programme 616 de la Famille Sandoz-Monique de Meuron pour la relève universitaire. We thank J. Bujan and

617 G. Fenn-Moltu and two anonymous reviewers for helpful comments on an earlier version of 618 the manuscript.

619 


\section{Funding}

623 This work was funded by the Swiss Canton Vaud, the Fond National Suisse, and the

624 Programme de la Famille Sandoz-Monique de Meuron pour la relève universitaire.

\section{Conflicts of interest}

The authors declare no conflicts of interest.

\section{Availability of data and material}

The data that support the findings of this study are openly available at https://github.com/JGippet/Tmagnum_impacts.

\section{Code availability}

The R code and data used to perform statistical analyses and associated figures are openly available at https://github.com/JGippet/Tmagnum_impacts.

\section{Authors' contributions}

J.M.W.G. and C.B. designed the study. L.G. carried out field sampling. L.G. and J.M.W.G. identified the ants. J.M.W.G. and L.G. carried out data processing and statistical analyses. All authors wrote the manuscript.

\section{Ethics approval}

No ethic approval was needed

\section{Consent to participate}

Not applicable

\section{Consent for publication}

Not applicable 
652

653

654

655

656

657

658

659

660

661

662

663

664

665

666

667

668

669

670

671

672

673

674

675
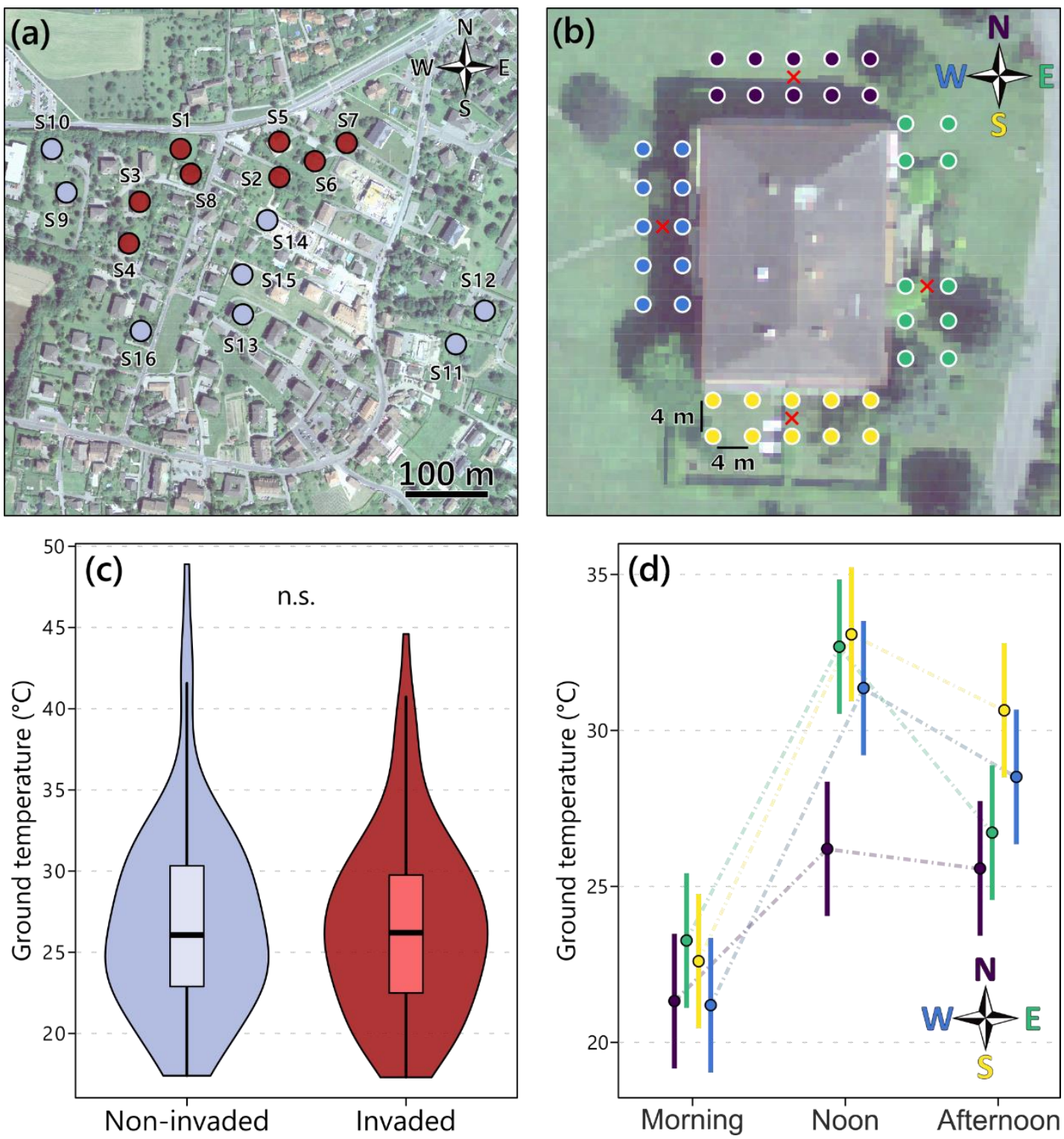

Fig. 1. Sampling design. (a) Position of the eight invaded (dark-red dots) and the eight noninvaded (light blue dots) sampling sites; (b) A typical sampling site composed of a green space surrounding a building. Baits (colored dots) were placed in a standardized way around the buildings. The red crosses indicate where ground temperature was measured for each sampling event; (c) Average ground temperature in invaded and non-invaded sampling sites; (d) Estimation of ground temperature depending on time and building side (according to the best fitting model: Temperature $\sim$ Time $*$ Side; marginal $R^{2}=0.53$ ). 

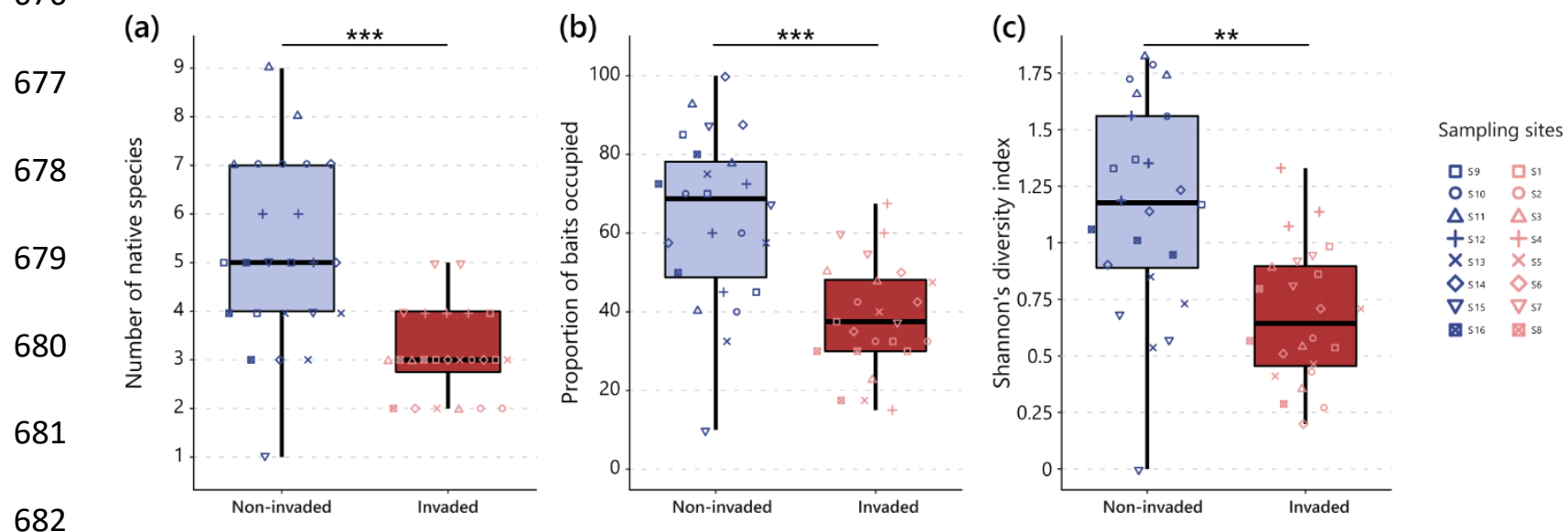

683 Fig. 2. Impact of Tapinoma magnum on (a) the richness, (b) the relative abundance and (c) the 684 diversity of native ant species. Coloured boxes contain $50 \%$ of the data (the median is the 685 central thick horizontal line) and whiskers contain the lowest and highest $25 \%$ of the data. Data 686 points are represented as symbols (horizontally jittered for visual purpose). For comparisons 687 between groups, **: $\mathrm{P}<0.01, * * *: \mathrm{P}<0.001$. 


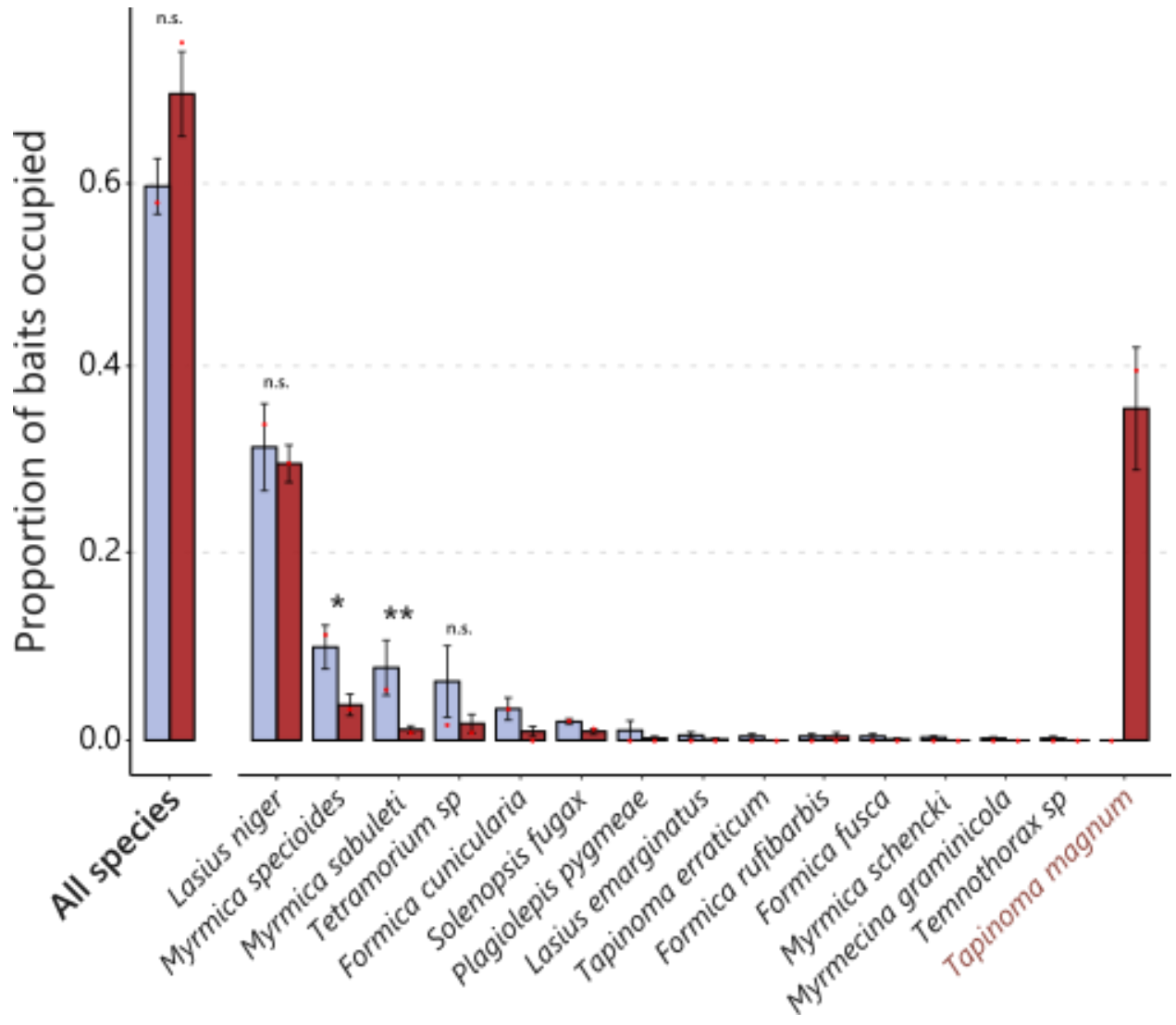

699

700 Fig. 3. Coloured bars represent the mean proportion of baits occupied by ants in invaded $(N=$ 701 8; dark red) and non-invaded ( $N=8$; light blue) sites. Error bars represent standard errors 702 around the mean and red dots are median values for each group. For comparisons between groups, n.s.: non-significant, *: $\mathrm{P}<0.05, * *: \mathrm{P}<0.01$.

704 
707

708

709

710

711

712

713

714

715

716

717

718

719

720

721

722

723

724

725

726

727

728

729 (a)

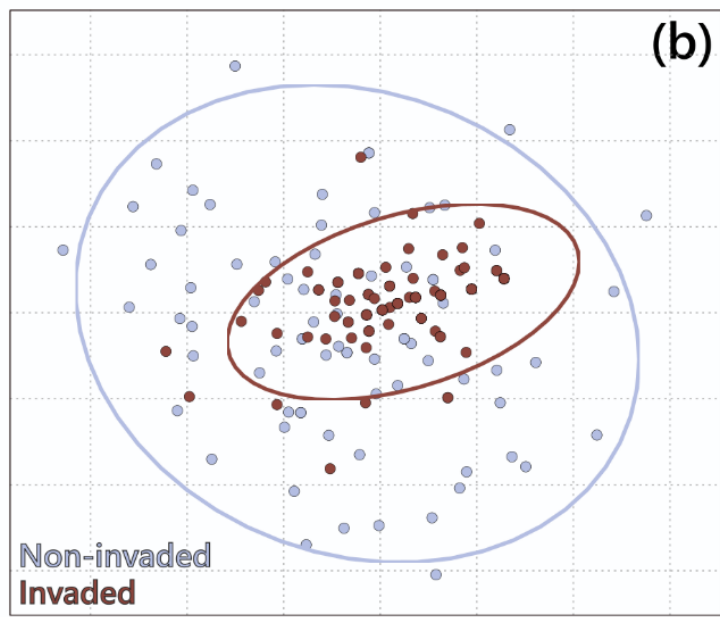

(c)

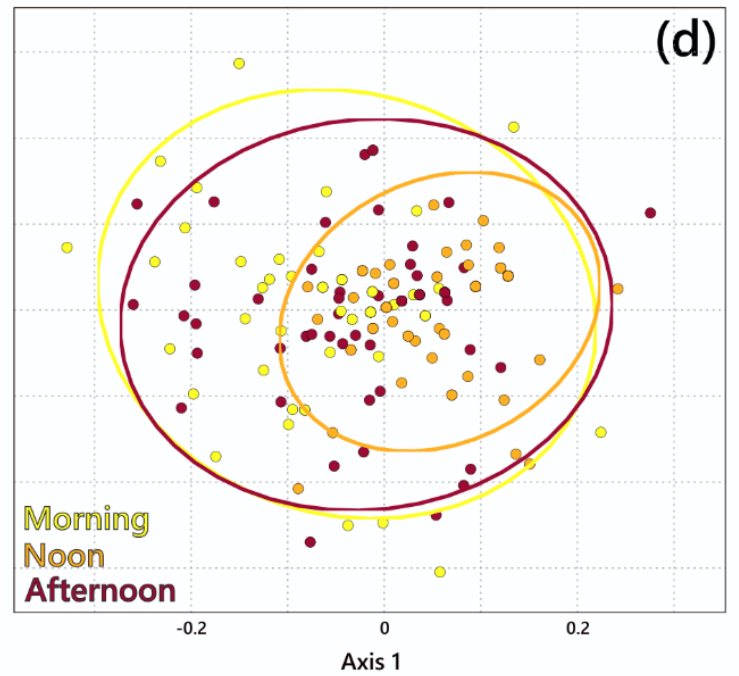

Fig. 4. Composition of native ant communities. (a) Arrows represent the contribution of each species on each axis of a non-metric multidimensional scaling (NMDS) biplot. (b, c, d) Dots $(N=192)$ represent the ant communities at each side of building and time of the day for each sampling site ( 16 sampling sites $* 3$ times $* 4$ sides). Dots were coloured to assess the difference in ants' community composition between (b) invaded and non-invaded sites, (c) side of building (North, East, South, West) and (d) time of day (morning, noon, afternoon). Ellipses include $95 \%$ of the dots of each group. 


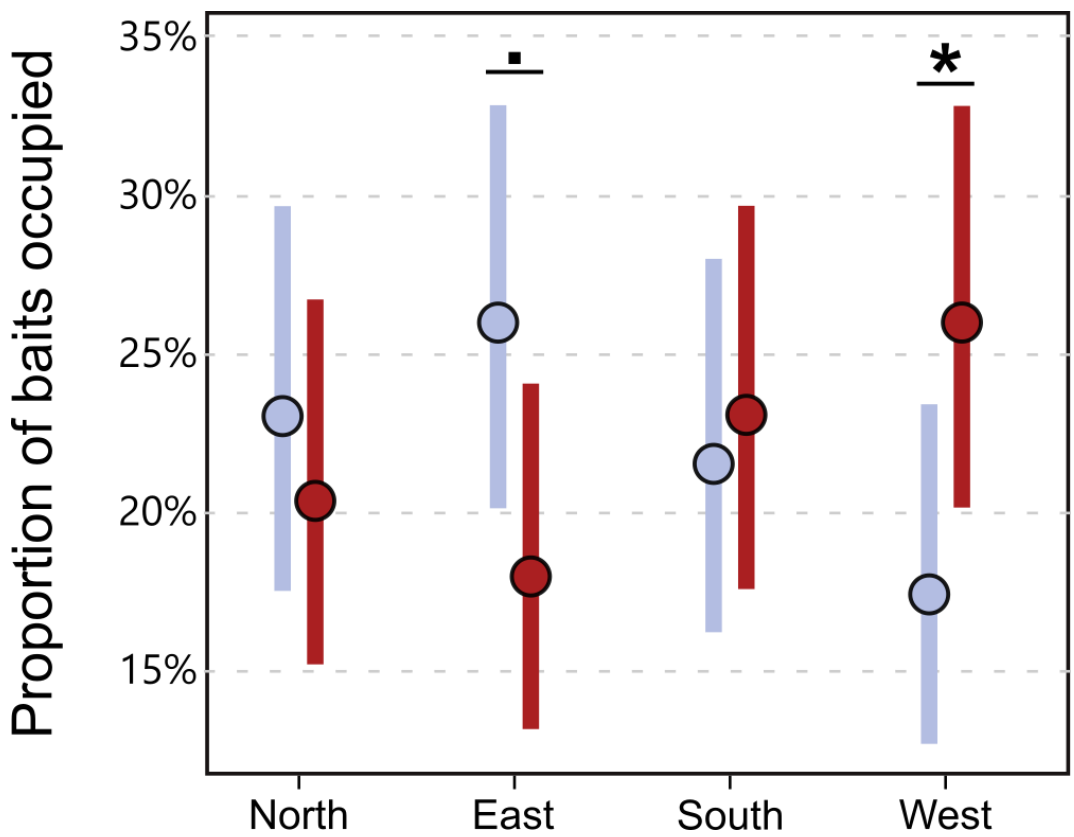

739

740 Fig. 5. The effects of Tapinoma magnum's invasion (invaded sites in red and non-invaded sites 741 in blue) on the proportion of baits occupied by the native ant L. niger depends on the side of 742 the building. Dots and bars are mean $\pm 95 \%$ CI estimations of the best-fitting model (Table 1).

743 Asterisks indicate significant differences between invaded and non-invaded sites $(\because P<0.1, *$ : $744 \quad P<0.05)$. 
747 Table 1. Effects of T. magnum's invasion (i.e., invaded vs non-invaded), time of the day 748 (morning, noon, afternoon) and exposition (north, east, south, west) on the proportion of baits 749 occupied, at each building sides, by Lasius niger, Myrmica specioides, Myrmica sabuleti, 750 Tetramorium sp. ( $N=192$ building sides) and Tapinoma magnum (only in invaded sites; $N=$ 75196 building sides). Ten baits were deposited at each building side during each sampling events 752 (Fig. 1, Fig. S1). Dark blue cells indicate significant effects $(p<0.05)$. Models' statistical 753 details are in Table S1.

754

755

756

757

758

759

760

761

762

763

764

\begin{tabular}{|c|c|c|c|c|c|c|c|}
\hline & \multicolumn{7}{|c|}{$\begin{array}{c}\text { Probability of baits } \\
\text { occupied }\end{array}$} \\
\hline & \begin{tabular}{|c|} 
\\
\\
$\frac{0}{0}$ \\
$\frac{0}{n}$ \\
$\frac{\pi}{ \pm}$ \\
$\leq$
\end{tabular} & $\stackrel{\oplus}{\models}$ & $\begin{array}{c} \\
0 \\
\frac{0}{0} \\
\frac{0}{0} \\
0 \\
\frac{5}{0} \\
\frac{0}{5} \\
\infty\end{array}$ & 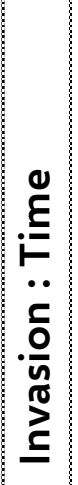 & 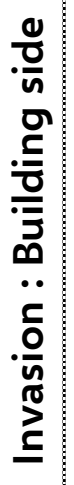 & 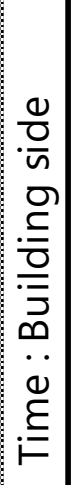 & 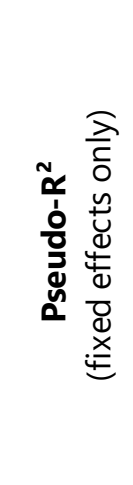 \\
\hline Tapinoma magnum & & & & & & & $0.01(0)$ \\
\hline Lasius niger & & & & & & & $0.03(0.027)$ \\
\hline Myrmica specioides & & & & & & & $0.21(0.2)$ \\
\hline Myrmica sabuleti & & & & & & & $0.29(0.27)$ \\
\hline Tetramorium sp. & & & & & & & $0.18(0.12)$ \\
\hline
\end{tabular}

765

766

767 
768 Table S1. Analyses of deviance (Type III Wald $\chi^{2}$ tests) of the best fitting models of the 769 proportion of baits occupied (Binomial GLMs) by each native ant species $(N=192$ building 770 sides and 16 sampling sites) and T. magnum ( $N=96$ building sides and 8 sampling sites) (See 771 Table 1).

772

773

774

775

\begin{tabular}{|c|c|c|c|c|c|c|}
\hline \multirow{16}{*}{ 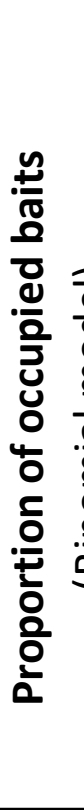 } & \multirow{16}{*}{ 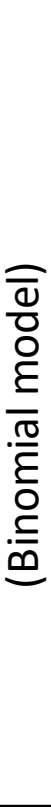 } & Species & Best model & $\chi^{2}$ & df & $P$ \\
\hline & & \multirow{5}{*}{ Lasius niger } & (Intercept) & 28.87 & 1 & $<0.0001$ \\
\hline & & & Invasion & 0.4 & 1 & 0.53 \\
\hline & & & Building side & 7.04 & 3 & 0.07 \\
\hline & & & Time of day & 22.23 & 2 & $<0.0001$ \\
\hline & & & Invasion : Building side & 13.45 & 3 & 0.004 \\
\hline & & & (Intercept) & 43.05 & 1 & $<0.0001$ \\
\hline & & Myrmica specioides & Invasion & 4.79 & 1 & 0.03 \\
\hline & & & Time of day & 29.5 & 2 & $<0.0001$ \\
\hline & & & (Intercept) & 39.07 & 1 & $<0.0001$ \\
\hline & & Murmica sahuleti & Invasion & 7.66 & 1 & 0.006 \\
\hline & & prymanca sandea & Building side & 16.84 & 3 & 0.0008 \\
\hline & & & Time of day & 12.03 & 2 & 0.002 \\
\hline & & Tetramorium on & (Intercept) & 73.3 & 1 & $<0.0001$ \\
\hline & & 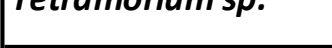 & Building side & 14.58 & 3 & 0.002 \\
\hline & & Tapinoma magnum & (Intercept) & 21.86 & 1 & $<0.0001$ \\
\hline
\end{tabular}

781

782 
784 Fig. S1. Position of the baits around each sampling sites. Large dots indicate building used as

785

786

787

788

789

790

791

792

793

794

795

796

797

798

799

800

801

802

803 invaded (red) and non-invaded (blue) sampling sites. Small dots give the approximate ( $\pm 1 \mathrm{~m})$ position of baits around the buildings. Their colour indicates the cardinal category at which they were assigned. Background satellite view is from Esri, Digital Globe, Earthstar Geographics.

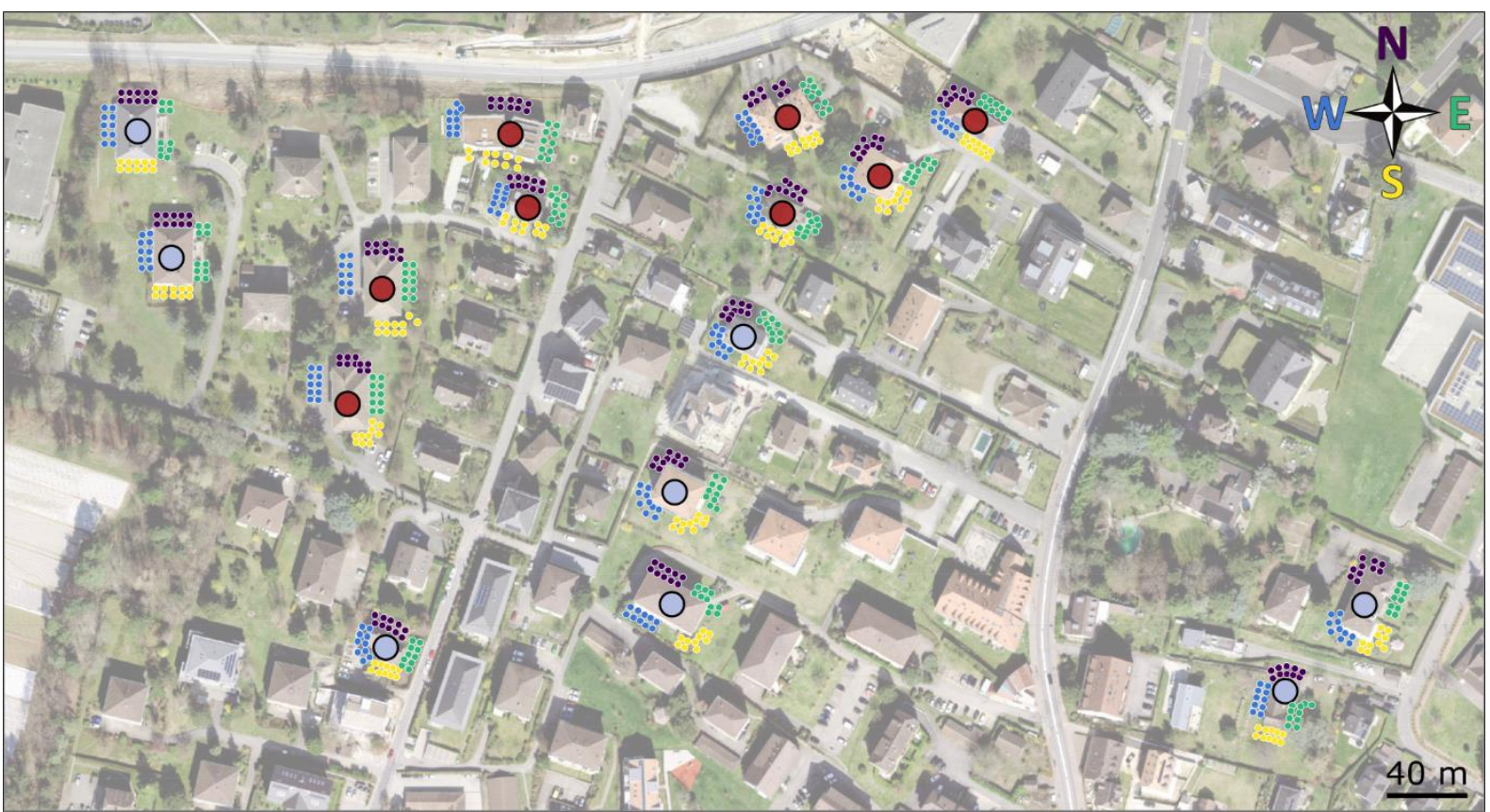
0 